\title{
Future Aspects of Intelligent Car Parking Based on Internet of Things
}

\author{
Muzhir Shaban Al-Ani, Zana Azeez Kakarash
}

Department of Information Technology, College of Science and Technology, University of Human Development, KRG, Iraq

\section{A B S T R A C T}

Nowadays, the crowded of cars leads to big challenges in many crowded cities. This leads to environmental pollution in addition to fuel consuming. In addition, it is very important to adapt all devices, vehicles, and objects to the environment of the internet of things (loT). In this case, it is difficult to find the nearest and shortest suitable path for car parking place. This approach aims to minimize the time for finding the car parking as well as reducing the traffic congestion. The implemented approaches try to support the driver to find near suitable car parking. The implemented approach based on intelligent aspects to achieve the performance of car parking with the future environment of loT. Localizing of the nearest car parking is an important issue in the future loT.

Index Terms: Car Parking, Intelligent Algorithm, Internet of Things, Real Time System

\section{INTRODUCTION}

More than 20 years ago, there is a small number of crowded cities, including the capitals of many countries [1], [2]. Nowadays, the crowded cities are increased and raised big challenges to control this situation [3], [4]. The population density is measured by a number of people per square kilometer, for this aspect Fig. 1 shows the most population density of cities over the world at 2015, these crowded cities at population leading to crowded roads [5], [6]. According to this high intensity of population distribution, so this aspect leading to big amount of cars circulating these heavy roads crowded cites [7], [8], [9], [10]. This makes it urgent to find solutions for car parking [11], [12]. Today, the traditional car parking becomes inefficient to cover the advanced revolution in car industry [13], [14].

\begin{tabular}{|l|l|}
\hline \multicolumn{2}{|c|}{ Access this article online } \\
\hline DOI: 10.21928/uhdjst.v2n1y2018.pp19-26 & $\begin{array}{l}\text { E-ISSN: 2521-4217 } \\
\text { P-ISSN: 2521-4209 }\end{array}$ \\
\hline $\begin{array}{l}\text { Copyright @ 2018 Al-Ani and Kakarash. This is an open access article } \\
\text { distributed under the Creative Commons Attribution Non-Commercial } \\
\text { No Derivatives License 4.0 (CC BY-NC-ND 4.0) }\end{array}$ \\
\hline
\end{tabular}

The big growth of cars through cities causing many problems such as traffic congestion, time delay, and fuel consumption. These factors are affecting directly business, economy, and health and cause big losses on these issues. Hence, it is an efficient option to solve these problems, and when cars are directed to the near car parking, this aspect gives a good solution to the environment. In 2017 about one million vehicles were on Amman's streets between 9:00 am and 10:00 am according to an official at the Greater Amman Municipality.

This research aims try to study the traffic at Amman city according to a high number of cars circulated each day in this city. In addition, a significant number of cars comes from outside of Amman city each day. All these cars need to be find the nearest parking place, so this is the main objective of the research.

\section{LITERATURE REVIEWS}

As the number of vehicles growth rapidly, it becomes a big challenge to overcome this aspect. Many papers are published

Corresponding author's e-mail: Muzhir Shaban Al-Ani, Department of Information Technology, College of Science and Technology, University of Human Development, KRG. E-mail: Iraq muzhir.al-ani@uhd.edu.iq 


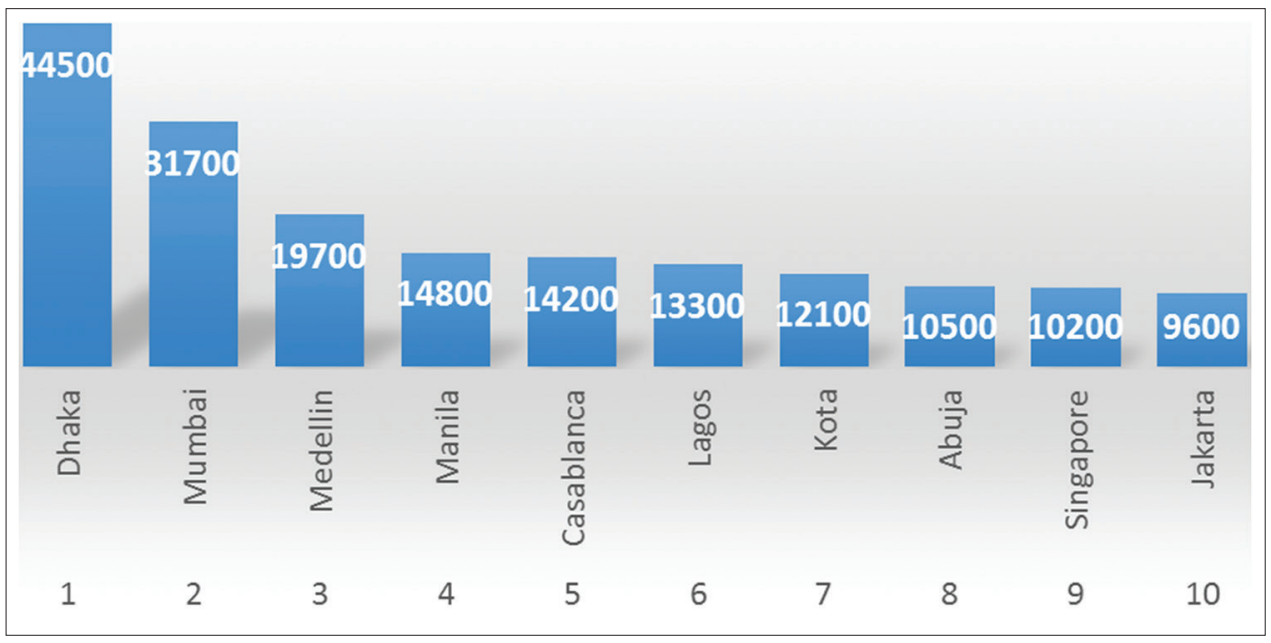

Fig. 1. Most population density of cities over the world at 2015

for design and implementation of different parking systems. Below some of literature reviews explained this issue.

Zhu et al. compared the energy available on the car dashboard to power the wireless labels in the car for asset tracking and parking applications. Three energy sources available on the dashboard of a vehicle were studied, namely vibrational energy, thermal energy, and light energy. The area available for the energy harvester is the same as that of a credit card. Simulations were performed to estimate the potential electric power that can be generated from the three energy sources. It has been found that a vibration harvester can generate tens of $\mu \mathrm{W}$ in all weather conditions. The other two types of energy harvesters can generate tens of $\mathrm{mW}$ per sunny day. However, the output power of a thermogenerator falls to 0 , while the power density of a solar cell falls to $40 \%$ in a cloudy or rainy climate [15].

Shin et al. proposed algorithm helps drivers find the most appropriate parking given the real-time status of parking facilities in a city. To suggest the most appropriate parking, several factors are taken into account, such as the distance from the guided parking, the walking distance from the guided parking to the destination, the expected parking costs, and the congestion caused by the parking guide. To evaluate the effectiveness of the proposed algorithm, simulation tests were performed. The proposed algorithm maximizes the use of a city's space resources and reduces unnecessary energy consumption and $\mathrm{CO}_{2}$ emissions from roving cars, as it is designed to effectively control parking use and reduce congestion [16].

Levy et al. presented PARK FIT, a new algorithm for estimating urban parking patterns based on a spatially explicit high-resolution vision of the supply and supply of urban parking that is inherently heterogeneous. This system was used to assess the adequacy of the demand for overnight parking and parking capacity in the city of Bat Yam, both currently and as part of the Bat Yam 2030 Master Transportation Plan using high-resolution data obtained. Then, they analyze the capabilities and limitations of this system and provide it as a free software based on ArcGIS [17].

Belloche purposed a model to search time for on-street parking. The modeling is based on Axhausen's proposal for off-street parking, but the specific characteristics of street parking allow several models to be taken into account to estimate the search time for parking on the street. These models face a survey carried out in several districts of Lyon. The results of this confrontation provide interesting conclusions about the modeling of the investigation time of street parking, validation, and other research needs to improve the solidity of the model [18].

Alkheder et al. focused on two aspects. First, a survey was prepared and distributed to 500 participants as part of a project to identify the scale of the parking problem in Abu Dhabi. Then, a technical framework was developed to develop a smart mobile application to improve the indoor parking management system in Abu Dhabi. The results indicate that the proposed mobile application will help to reduce the time lost in the search for parking and increase the efficiency of the parking system in Abu Dhabi [19].

Atif et al. presented a continuous work program that contributes to new business solutions and cutting-edge research impacts. They reveal a PSP-multilayer business 
model through interdisciplinary research blocks where the original results are expected in each layer. This article reveals a work in progress to take advantage of private properties for parking, to relieve stress in public bodies, create new sources of income, and attract new entities in the middle market. The internet of things (IoT) paradigm extends the reach of smart cloud-based parking services in smart cities, with new applications that better regulate car parking traffic [20].

Bischoff et al. demonstrated the integration of a parking search simulation in Multi-Agent Transport Simulation. This includes the integration in the agent simulation logic using a daily planning methodology, separation of car trips of several segments for each travel segment, a parking search behavior, and a data structure for each trip segment. The parking search model is applied in a case study for an area in Berlin, Germany. Compared to a standard simulation without parking search, the results suggest that parking search traffic represents up to $20 \%$ of the total traffic in a residential area and has a significant impact on the total travel time of the agents traveling in car [21].

Christiansen et al. used the data set from the 2013 National Travel Survey (NTS), which includes approximately 60,000 interviews of people 13 years of age and older. A sample of more than 2000 inhabitants of the city of this NTS was selected for an extensive parking survey. They asked detailed questions about the parking of the house. NTS 2013 and the parking survey were merged, and travel patterns and contextual variables were linked to detailed information on parking availability. This has provided an excellent opportunity to analyze how variations in parking facilities affect the travel and ownership of a car [22].

Thomas and Kovoor explained the valuable time and fuel of the customer that is wasted and they have little time to do their shopping. Authorities are struggling to cope with this situation, even after designating more personnel to manage traffic in the bay. A smart parking system that could raise this problem is an urgent requirement for the mall. This document throws light on this issue when proposing a new prototype for the intelligent parking system of automobiles. A genetic algorithm approach has been adopted to solve the problem of programming the vehicle in the parking area [23].

Nourinejad et al. introduced the optimal design of the minimum relocation car parks; they presented a non-linear mixed program that treats each island of the car park as a system of queues. They solve the problem using the decomposition of Benders to obtain an exact answer and present a heuristic algorithm to find a reasonable upper limit of the mathematical model. They showed that autonomous parking can reduce the need for parking spaces by an average of $62 \%$ and up to $87 \%$. This revitalization of the space previously used for parking can be socially beneficial if the parking lots are converted into commercial and residential uses [24].

Most of the related works are concentrated on the parking spaces, parking positions, the relationship between population

\begin{tabular}{|c|c|c|c|c|c|c|c|c|c|}
\hline \multicolumn{10}{|c|}{$\begin{array}{c}\text { TABLE I } \\
\text { First Level of Map Division }\end{array}$} \\
\hline s1 & 1 & 2 & 3 & 4 & 5 & 6 & 7 & 8 & 9 \\
\hline 2 & $\mathrm{~S} 1(2,1)$ & $\mathrm{S} 1(2,2)$ & $\mathrm{S} 1(2,3)$ & $\mathrm{S} 1(2,4)$ & $\mathrm{S} 1(2,5)$ & $\mathrm{S} 1(2,6)$ & $\mathrm{S} 1(2,7)$ & $\mathrm{S} 1(2,8)$ & $\mathrm{S} 1(2,9)$ \\
\hline 3 & $\mathrm{~S} 1(3,1)$ & $S 1(3,2)$ & S1 $(3,3)$ & $\mathrm{S} 1(3,4)$ & $\mathrm{S} 1(3,5)$ & $\mathrm{S} 1(3,6)$ & $\mathrm{S} 1(3,7)$ & $\mathrm{S} 1(3,8)$ & $\mathrm{S} 1(3,9)$ \\
\hline 4 & $\mathrm{~S} 1(4,1)$ & $\mathrm{S} 1(4,2)$ & $\mathrm{S} 1(4,3)$ & $\mathrm{S} 1(4,4)$ & $\mathrm{S} 1(4,5)$ & $\mathrm{S} 1(4,6)$ & $\mathrm{S} 1(4,7)$ & $\mathrm{S} 1(4,8)$ & $\mathrm{S} 1(4,9)$ \\
\hline 5 & $\mathrm{~S} 1(5,1)$ & $\mathrm{S} 1(5,2)$ & $\mathrm{S} 1(5,3)$ & $\mathrm{S} 1(5,4)$ & $\mathrm{S} 1(5,5)$ & $S 1(5,6)$ & $\mathrm{S} 1(5,7)$ & $\mathrm{S} 1(5,8)$ & $\mathrm{S} 1(5,9)$ \\
\hline
\end{tabular}

\begin{tabular}{|c|c|c|c|c|c|c|}
\hline \multicolumn{7}{|c|}{$\begin{array}{c}\text { TABLE II } \\
\text { Second Level of Map Division }\end{array}$} \\
\hline S11 & 1 & 2 & 3 & 4 & 5 & 6 \\
\hline 2 & $\mathrm{~S} 11(2,1)$ & $\mathrm{S} 11(2,2)$ & $\mathrm{S} 11(2,3)$ & $\mathrm{S} 11(2,4)$ & $\mathrm{S} 11(2,5)$ & $\mathrm{S} 11(2,6)$ \\
\hline 3 & $\mathrm{~S} 11(3,1)$ & $\mathrm{S} 11(3,2)$ & $\mathrm{S} 11(3,3)$ & $\mathrm{S} 11(3,4)$ & S11 $(3,5)$ & $\mathrm{S} 11(3,6)$ \\
\hline 4 & $\mathrm{~S} 11(4,1)$ & $\mathrm{S} 11(4,2)$ & $\mathrm{S} 11(4,3)$ & $\mathrm{S} 11(4,4)$ & $\mathrm{S} 11(4,5)$ & $\mathrm{S} 11(4,6)$ \\
\hline
\end{tabular}


and number of cars and number of car parking, transport simulation, smart parking, etc. This research aims to design an effective control parking to minimize time as possible and to reduce congestion.

\section{METHODOLOGY}

The methodology of this approach including Amman city as a case study to design and implement the system, car parking design in which the design of the overall building with networks and sensors, and finally the IoT that deal with the adaptation of the system through the future aspects of IoT.

\section{A. Amman City: Case Study}

Amman city is selected as a case study to demonstrate the implemented approach. Amman is the capital of Jordan. Amman is situated in north-central of Jordan. Amman has a population of 4,007,526 and a land area of $1680 \mathrm{~km}^{2}$. Today, Amman is a major tourist destination in the region, particularly among Arab and European tourists.

The number of vehicles registered with the Department of Licensing of Drivers and Vehicles reached 1,420,951 vehicles at the end of last January 2016, and consequently, there are about one million vehicles in Amman. Hence, there are about 595 vehicles in each $1 \mathrm{~km}^{2}$.
The first step (first level of squares) (Table I) Amman map is divided into a square $(9 * 6=54)$, according to Amman land area of $1680 \mathrm{~km}^{2}$, so each square is about $31.1 \mathrm{~km}^{2}$, and each square is of size $5.58 * 5.58 \mathrm{~km}$ as shown in Fig. 2. In addition, there are about 18,518 vehicles in each square, but this number is as an average only. Really the city center is more crowded and has more streets than the border.

The second step (second level of squares) (Table II) in which each square of the first level is divided into smaller squares $(6 * 6=36)$, so each small square $(\mathrm{S} 11)$ has the area of about $0.864 \mathrm{~km}^{2}\left(864000 \mathrm{~m}^{2}\right)$. At this level, the square size is about $930 * 930 \mathrm{~m}$.

The third step (third level of squares) (Table III) in which each square of the second level is divided into more smaller squares $(6 * 6=36)$, so each more smaller square (S111) has the area of about $24000 \mathrm{~m}^{2}$. At this level, the square size is about $155 * 155 \mathrm{~m}$.

According to the third level, there are 36 squares of size $155^{*} 155 \mathrm{~m}$, so if this size is divided into three parts as shown in Fig. 3. The car parking's are situated at the corners of a square situated at the center of each bigger square (denoted by green color), this means any driver position can reach its parking destination within a distance between 44 and $62 \mathrm{~m}$.

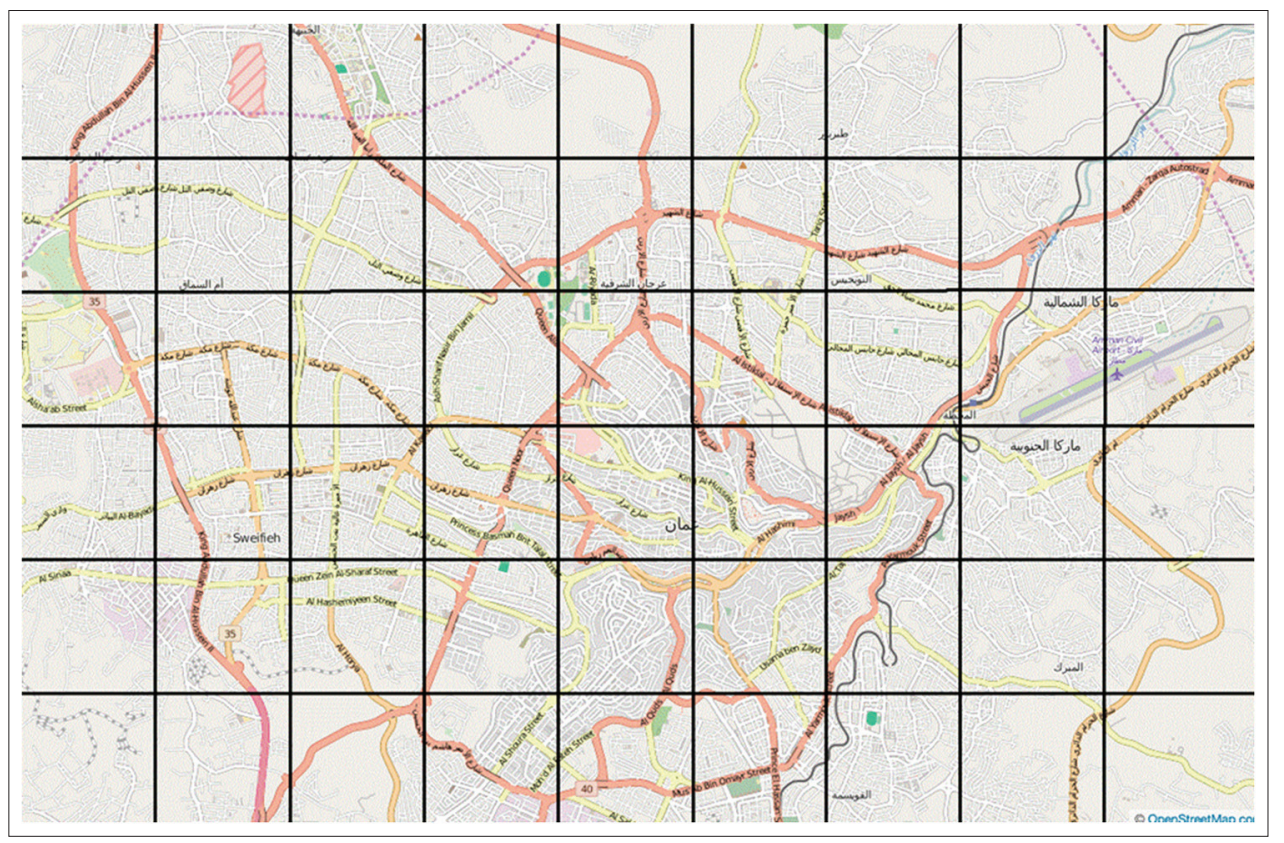

Fig. 2. Amman map divided into square 


\section{B. Car Parking Design}

Car parking design is divided into two parts: Inside car parking and outside car parking. The inside design started with the area of $25 * 25 \mathrm{~m} 2$ with ten plants. The structure of each plant is divided into 10 car places with two sides. Each car park is equipped by one digit screen (0-9) and a lead sensor in which the green color indicates empty place and the blue color indicates the busy place as shown in Fig. 4.

At the gate of each plant, there is a screen indicates the empty places in that plant, in addition, there is a screen at the main gate of the garage indicates which plant have empty places. All these information collected directly from sensors located in each plant and each car parking place.

The outside car parking is a communications system that has information of all the parking places at the city. That information including size of the park, have empty places or no, the distance from the driver position, and the guided direction to the destination.

\section{IoT through Raspberry Pi}

The future of the world is directed to the IoT, so the implemented system has the ability to synchronize with the IoT. The overall system is constructed from devices, sensors, and networks, so it is so easy to adapt this system with Io'T.

The main part of this approach is adapting the Raspberry Pi which has the ability to operate in real time. Many generations of Raspberry Pi have been manufactured. The $1 \mathrm{G}$ of Raspberry Pi-1 was released in February 2012; the $2 \mathrm{G}$ is Raspberry Pi-2 which added more RAM was released in February 2015, and the 3G of Raspberry Pi-3 was released in February 2016 that adapted onboard WiFi and Bluetooth.

Raspberry Pi-3 is a microcomputer that has the ability to work in real time including managing all the required operations of the implemented system such as detection, capturing, and tracking of information. Raspberry Pi-3 has the ability to simulate various applications in our daily life with a flexible platform. The architectural design of Raspberry Pi is shown in Fig. 5. The hardware car parking implemented the system using Raspberry Pi is shown in Fig. 6. This system you have the ability to interact, transiting and receiving, control, and working at the real time. That means all the functions (according to car parking information and processing) through the implemented approach can be run at a real time without any delay.

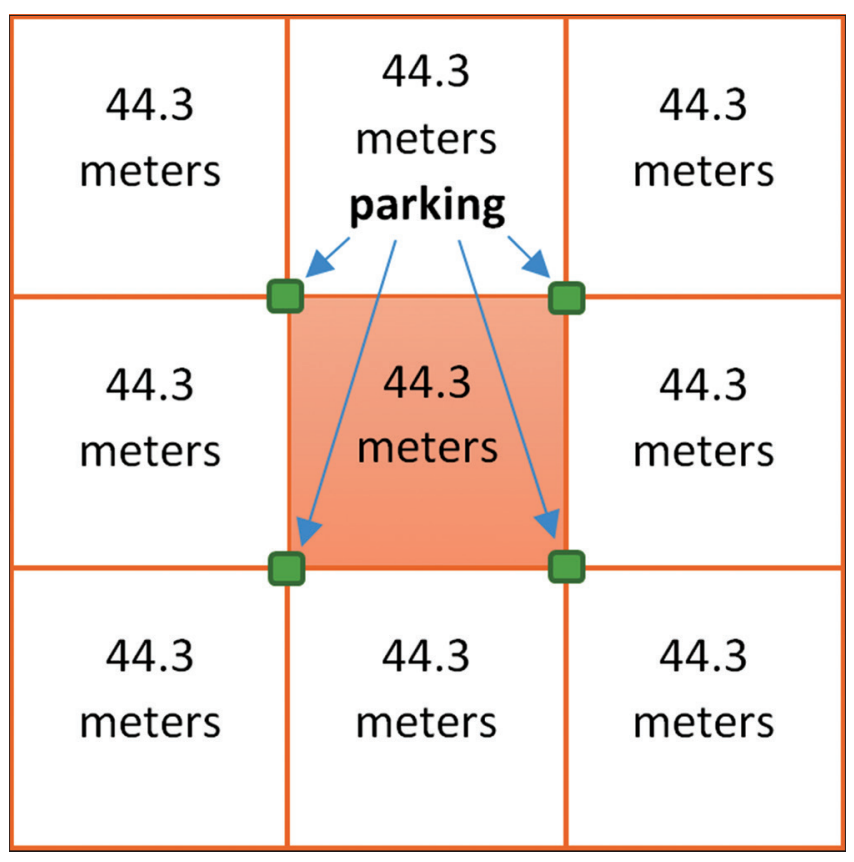

Fig. 3. Car parking places

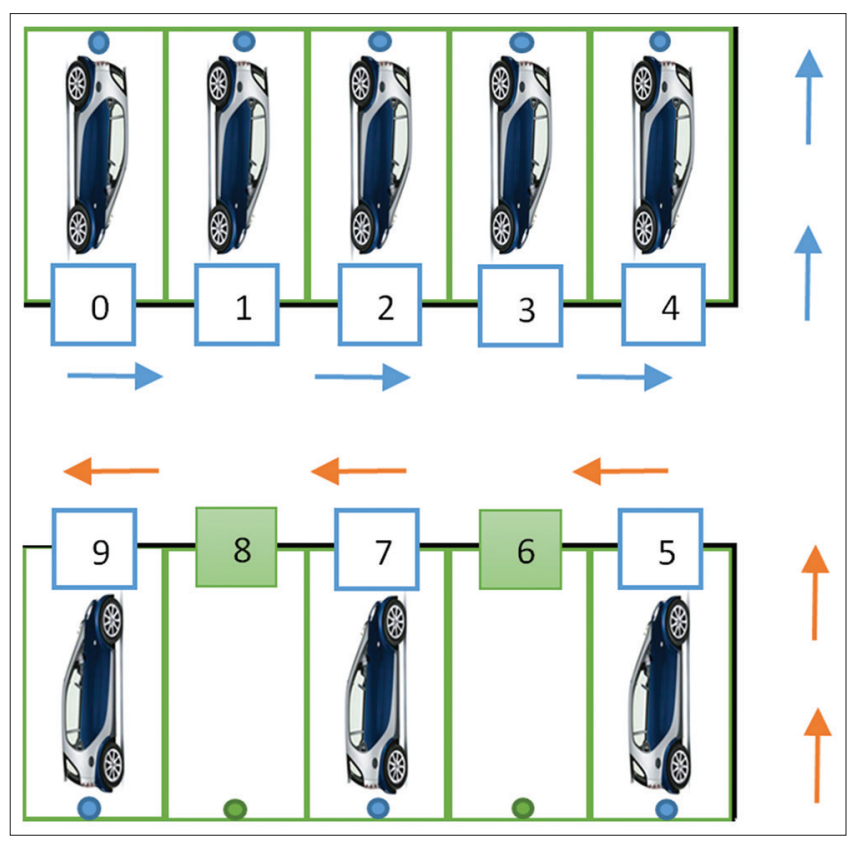

Fig. 4. One plant of parking building

\section{Intelligent Car Parking Approach}

The intelligent car parking approach based on the following aspects:

- Equipped each plant with sensors situated in each car parking place for carrying the information of the car parking place that is busy or empty. 


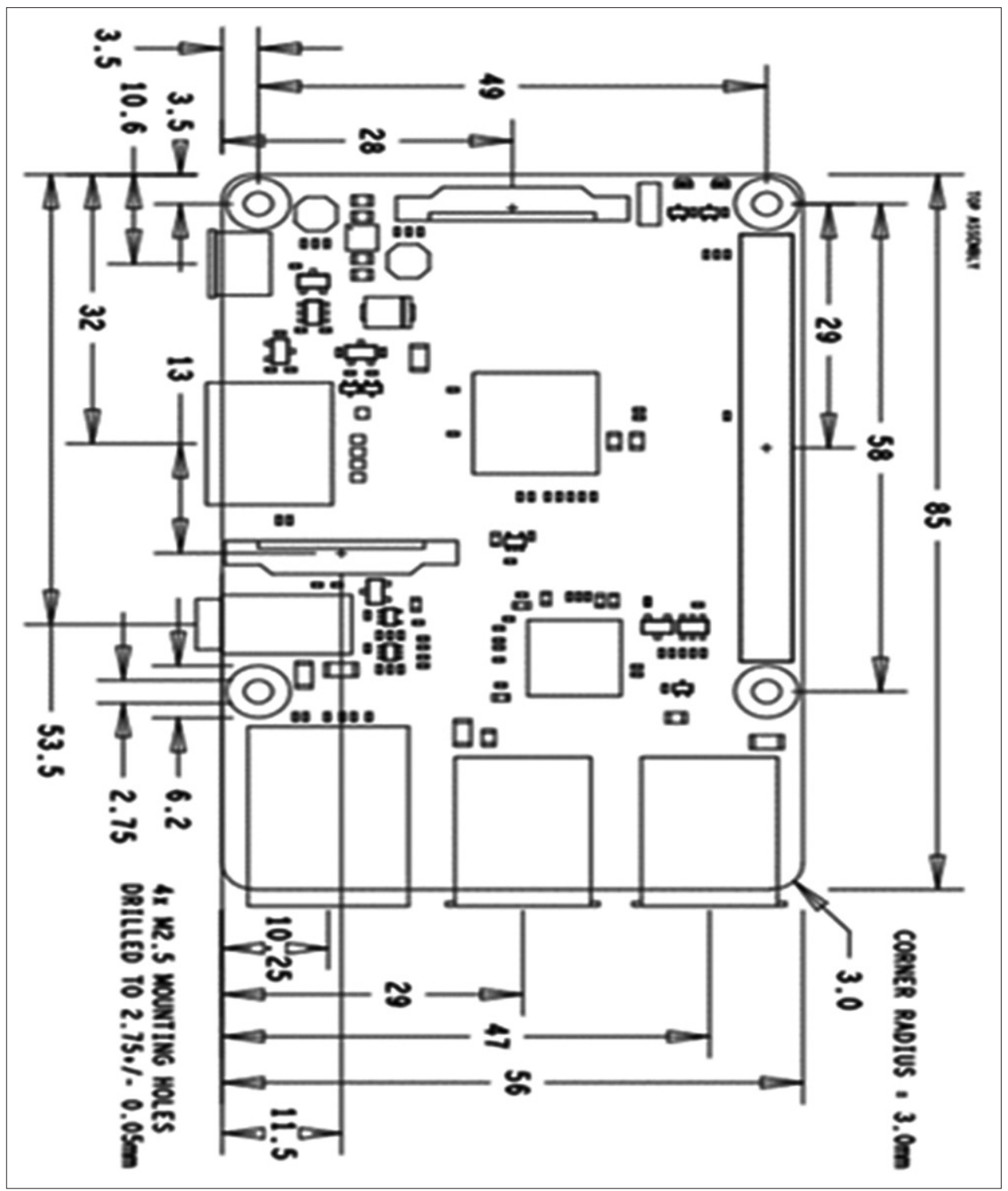

Fig. 5. Raspberry Pi architecture

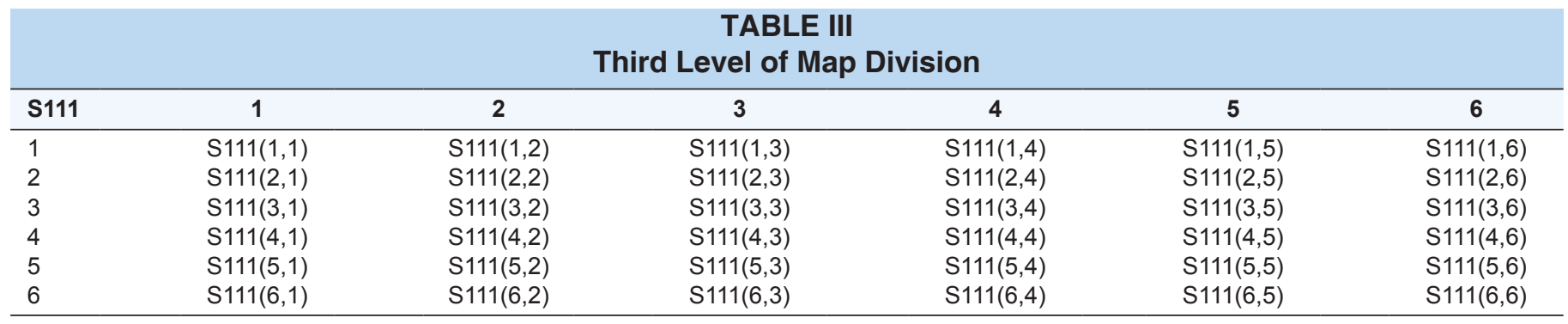

- Equipped each plant with one digit screens situated at the gate of each car parking place for indication the car parking place is busy or empty.
- Equipped each plant by a screen situated at the gate of each plant for indication the car parking is busy or empty. 
- Equipped each plant by Raspberry Pi 3 situated at the gate of each plant. This device works as a microcomputer to control the operation of the overall system.

- Equipped each plant by the powerful router to achieve a wireless network between all equipment's of the plant.

- Equipped a network connection between the 10 plants into a central unit that controls and transmit data of the main part of the plants.

- Equipped an efficient screen on the main gate of the garage to display the situation of the garage instantaneously.

\section{DISCUSSIONS}

The overall system (mobile driver) can be installed on smart mobile devices, in which the driver with his mobile device can access the car parking system to allocate the suitable place for his car. The first part of this approach starts working when the driver starts to access the car parking system. This system allocates on the two nearest car parking places with empty places, so the driver must select the most suitable one in which he will have all the information about that park including position, distance, and direction as shown in Fig. 7.

The second part of this approach starts working when the car is reaching the main gate of the garage, in which the system has enough information about the places so the driver will get a number associated with a number of the car place, so the driver guides his car to the indicated place. A simple security issue is suggested through integrating and merging both the car license plate number and the associated number to generate a secure number that can verify when there is any problem.

\section{CONCLUSIONS}

The crowded cities are leading to many environmental problems such as ambient pollution. The aim of adequate car parking leading to localize the nearest car parking position in which reduce pollution in crowded cities, reduce the traffic congestion and minimize the required time to reach the destination. The proposed car parking system has two main subsystems. The external subsystem that covers all the communications between cars and guiding cars to its nearest park. The internal subsystem that covers all the function enter the park and guided the car to its final destination. The implemented system compensate and minimize the time for finding the car parking as well as reducing the traffic congestion, that leading to minimize the pollution.

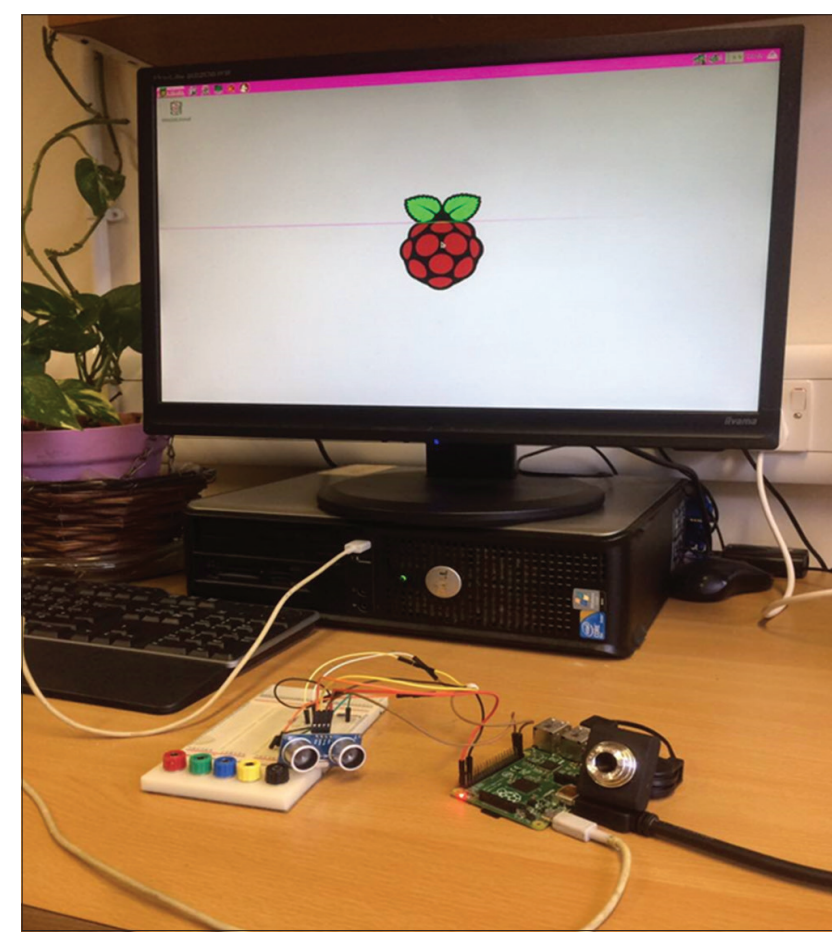

Fig. 6. System connection

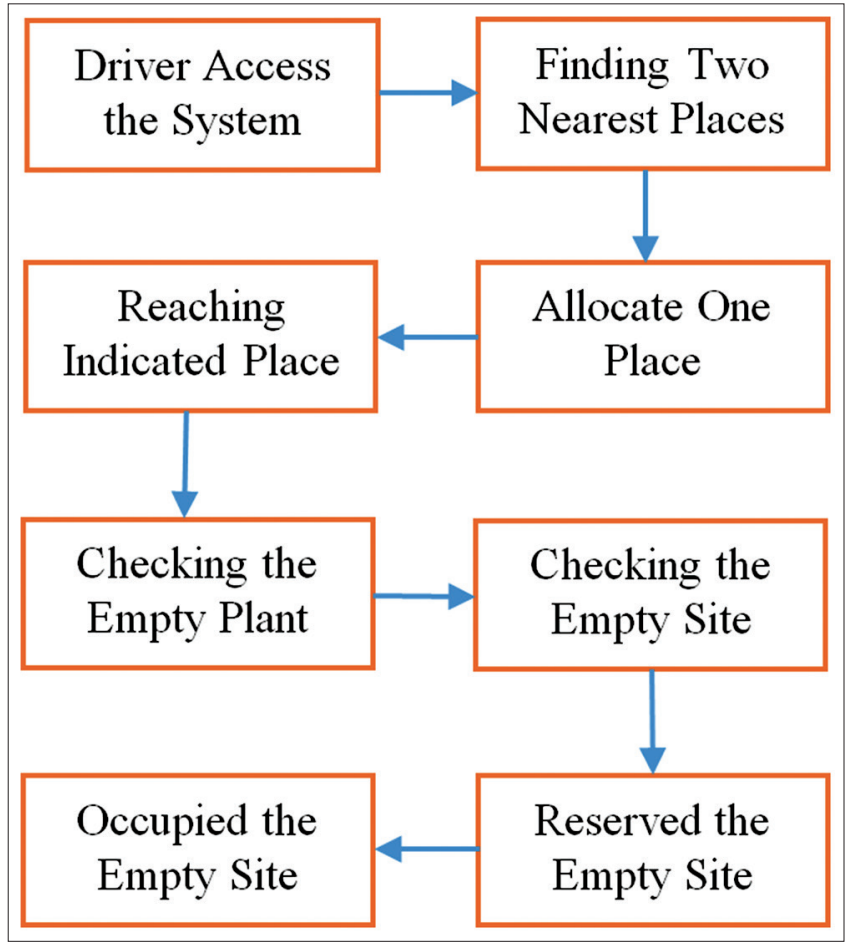

Fig. 7. The implemented system procedure

Integrating and indexing cars and car parks leading to solve an important issue in the future IoT. This research studies 
the overall environment of Amman city and the best arrangement of the car parking positions. The proposed future works of this research are how to realize these factors in a real environment.

\section{REFERENCES}

[1] J. Gimeno, C. Portalés, I. Coma, M. Fernández and B. Martínez. Combining traditional and indirect augmented reality for indoor crowded environments. A case study on the Casa Batlló museum. Computers and Graphics, vol. 69, pp. 92-103, 2017.

[2] D.J.W. Barnaby, M.J. Rantala, E.F. Melo and R.C. Brooks. Beards and the big city: Displays of masculinity may be amplified under crowded conditions. Evolution and Human Behavior, vol. 38, no. 2, pp. 259-264, 2017.

[3] J. Rappaport. A productivity model of city crowdedness. Journal of Urban Economics, vol. 63, no. 2, pp. 715-722, 2008.

[4] A. Alahi, V. Ramanathan and L. Fei-Fei. Chapter 6: Tracking Millions of Humans in Crowded Spaces, Book Chapter, Group and Crowd Behavior for Computer Vision, 2017. pp. 115-135.

[5] M. Grove. Population density, mobility, and cultural transmission. Journal of Archaeological Science, vol. 74, pp. 75-84, 2016.

[6] D. de la Croix and P.E. Gobbi. Population density, fertility, and demographic convergence in developing countries. Journal of Development Economics, vol. 127, pp. 13-24, 2017.

[7] A. Gupta and V. Rastogi. Effects of various road conditions on dynamic behaviour of heavy road vehicle. Procedia Engineering, vol. 144, pp. 1129-1137, 2016.

[8] C. Men, R. Liu, F. Xu, Q. Wang and Z. Shen. Pollution characteristics, risk assessment, and source apportionment of heavy metals in road dust in Beijing, China. Science of the Total Environment, vol. 612, pp. 138-147, 2008.

[9] O. Stepanchuk, A. Bieliatynskyi, O. Pylypenko and S. Stepanchuk. Surveying of traffic congestions on arterial roads of Kyiv city. Procedia Engineering, vol. 187, pp. 14-21, 2017.

[10] J. Lizbetin and L. Bartuska. The influence of human factor on congestion formation on urban roads. Procedia Engineering, vol. 187, pp. 206-211, 2017.

[11] T.T.M. Thanh and H. Friedrich. Legalizing the illegal parking, a solution for parking scarcity in developing countries. Transportation Research Procedia, vol. 25, pp. 4950-4965, 2017.
[12] R. Arnott and P. Williams. Cruising for parking around a circle. Transportation Research Part B: Methodological, vol. 104, pp. 357-375, 2017.

[13] M. Dodourova and K. Bevis. Networking innovation in the European car industry: Does the open innovation model fit? Transportation Research Part A: Policy and Practice, vol. 69, pp. 252-271, 2014.

[14] S. Cherubini, G. lasevoli, and L. Michelini. Product-service systems in the electric car industry: Critical success factors in marketing. Journal of Cleaner Production, vol. 97, pp. 340-349, 2015.

[15] D. Zhu, L. Wang, J. Henaut and S. Beeby. Comparisons of energy sources for autonomous in-car wireless tags for asset tracking and parking applications. Procedia Engineering, vol. 87, pp. 783-786, 2014.

[16] J.H. Shin and H.B. Jun. Astudy on smart parking guidance algorithm. Transportation Research Part C: Emerging Technologies, vol. 44, 299-317, 2014.

[17] N. Levy and I. Benenson. GIS-based method for assessing city parking patterns. Journal of Transport Geography, vol. 46, pp. 220-231.

[18] S. Belloche. On-street parking search time modelling and validation with survey-based data. Transportation Research Procedia, vol. 6, pp. 313-324, 2015.

[19] S.A. Alkheder, M.M. Al Rajab and K. Alzoubi. Parking problems in Abu Dhabi, UAE toward an intelligent parking management system "ADIP: Abu Dhabi Intelligent Parking". Alexandria Engineering Journal, vol. 55, no. 3, 2679-2687, 2016.

[20] Y. Atif, J. Ding, and M.A. Jeusfeld. Internet of things approach to cloud-based smart car parking. Procedia Computer Science, vol. 98, pp. 193-198, 2016.

[21] J. Bischoff and K. Nagel. Integrating explicit parking search into a transport simulation. Procedia Computer Science, vol. 109, pp. 881-886, 2017.

[22] P. Christiansen, N. Fearnley, J.U. Hanssen and K. Skollerud. Household parking facilities: Relationship to travel behaviour and car ownership. Transportation Research Procedia, vol. 25, pp. 4185-4195, 2017.

[23] D. Thomas and B.C. Kovoor. A genetic algorithm approach to autonomous smart vehicle parking system. Procedia Computer Science, vol. 125, pp. 68-76, 2018.

[24] M. Nourinejad, S. Bahrami and M.J. Roorda. Designing parking facilities for autonomous vehicles. Transportation Research Part B: Methodological, vol. 109, pp. 110-127, 2018. 